\title{
Uma governança orientada por diretrizes de governo aberto aprimora o valor público de programas governamentais?
}

\author{
Cristina Borges Mariani ${ }^{1}$ \\ Antônio Lassance ${ }^{2}$ \\ ${ }^{1}$ Ministério da Cidadania, Brasília - DF, Brasil \\ ${ }^{2}$ Instituto de Pesquisa Econômica Aplicada (Ipea), Brasília - DF, Brasil
}

$\mathrm{O}$ artigo analisa em que medida a introdução de princípios de governo aberto, ao promover mudanças na governança das políticas públicas, favorece a geração de valor público em programas governamentais. A partir de estudo de caso do programa Bolsa Família, com triangulação de métodos, é feito o rastreamento das alterações na governança do programa que estiveram alinhadas a princípios de governo aberto, aferindo até que ponto houve ou não uma maior geração de valor público pelo programa. O estudo conclui que o Bolsa Família, mais do que atender a normativos e adotar uma governança orientada por padrões genéricos, construiu seu próprio modelo (ou referencial) de governança aberta. Alguns aspectos cruciais desse modelo já coincidiam com princípios e diretrizes de governo aberto que só seriam consagrados posteriormente. As evidências são de que isso ocorreu pela necessidade prática de encontrar soluções que trouxessem agilidade e facilidades operacionais à implementação e à prestação de contas do programa, materializadas na forma de algumas de suas ferramentas de política, como o Cadastro Único. A pesquisa oferece ainda uma contribuição aplicada de operacionalização do conceito de valor público por meio, entre outras, da análise do acesso e do uso de dados abertos.

Palavras-chave: governança, governo aberto, valor público 


\section{¿La gobernanza guiada por pautas de gobierno abierto mejora el valor público de los programas gubernamentales?}

El artículo analiza en qué medida la introducción de principios de gobierno abierto, al promover cambios en la gobernanza de las políticas públicas, favorece la generación de valor público. Basado en un estudio de caso del programa Bolsa Família, con triangulación de métodos, se investigan los cambios en la gobernanza del programa que están en línea con los principios de gobierno abierto y se verifica en qué medida hubo una mayor generación de valor público por el programa. El estudio concluye que Bolsa Familia, más que cumplir normas y adoptar una gobernanza guiada por estándares genéricos, ha construido su propio modelo de gobernanza abierta. Algunos aspectos cruciales de este modelo ya coincidían con principios y lineamientos de gobierno abierto que solo serían consagrados más adelante. La evidencia es que esto ocurrió por la necesidad práctica de encontrar soluciones que aportaran agilidad y facilidades operativas a la implementación y rendición de cuentas del programa, materializado en la forma de algunas de sus herramientas de política, como el Registro Único de beneficiarios del programa. La investigación también ofrece una contribución aplicada para operacionalizar el concepto de valor público por medio del análisis del acceso y del uso de datos abiertos, entre otros mecanismos.

Palabras clave: gobernanza, gobierno abierto, valor público

\section{Does governance guided by open government guidelines enhance the public value of government programs?}

The article analyzes the extent to which the introduction of open government principles, by promoting changes in the governance of public policies, favors the generation of public value for government programs. Based on a case study of the Bolsa Família program, with a triangulation of methods, changes in the governance of the program that were aligned with the principles of open government are tracked and the measurement of the extent to which, or not, there was a greater generation of public value by the program. The study concludes that Bolsa Família which is more than just meeting norms and adopting governance guided by generic standards has built its own open governance model. Some crucial aspects of this model already coincided with open government principles and guidelines that would only be enshrined later. The evidence is that this occurred due to the practical need to find solutions that would bring agility and operational facilities to the implementation and accountability of the program, materialized in the form of some of its policy tools, such as the Single Registry. The research also offers an applied contribution to operationalize the concept of public value through, among others, the analysis of access and use of open data.

Keywords: governance, open government, public value 


\section{Introdução}

Este artigo tem como objetivo investigar a relação entre governança de políticas públicas e princípios de governo aberto na geração de valor público por programas governamentais. A pergunta de pesquisa consiste em saber em que medida a introdução de princípios de governo aberto, ao promover mudança na governança de políticas públicas, favorece ou não a geração de valor público por programas governamentais. A partir de estudo de caso do programa Bolsa Família, com triangulação de métodos, são analisadas em profundidade as alterações na governança do programa que estiveram alinhadas a princípios de governo aberto, identificando os resultados delas decorrentes.

Apesar da relevância que os temas do governo aberto e da governança adquiriram na última década, tanto como referenciais de análise quanto como agenda de muitos governos, poucos aprofundam a relação entre esses dois conceitos e a geração de valor público.

$\mathrm{O}$ artigo começa, nesta introdução, por contextualizar a proposta de governo aberto. Em seguida, apresenta os referenciais de análise, partindo dos conceitos de governo aberto, governança e valor público, e explicitando a teoria que os relaciona, indicando também a metodologia utilizada no estudo. Depois, são apresentadas as mudanças na governança do programa Bolsa Família que estiveram de fato alinhadas aos princípios de governo aberto. Finalmente, o estudo verificou que ferramentas e instrumentos de políticas públicas foram criados ou aprimorados a partir dessas mudanças e quais resultados indicaram melhorias na geração de valor público, associadas à maior transparência, participação e colaboração na interface com cidadãs e cidadãos.

\section{Referencial de análise e metodologia}

Os referenciais da "Parceria para Governo Aberto" (OGP) surgiram sob bases eminentemente normativas, sem uma clara explicitação de qualquer vinculação a teorias e arcabouços mais diretamente vinculados à literatura de políticas públicas. Isso não impediu essa iniciativa global de oferecer uma clara teoria do programa em seus pressupostos.

É factível supor que tais bases tenham incorporado, como pressupostos, parte essencial do debate sobre governança e gestão pública que se intensificou e reverberou amplamente nas décadas de 1990 e 2000. Alguns dos pilares desse debate eram 
exatamente o da maior transparência, da melhor "accountability", da qualificação da participação e colaboração cidadã nas políticas e programas e do aprimoramento da governança pública (DuTTON, 2011; HiLgers, Piller, 2011; LOPEZ, 2010; PETERS, 2008; FREDERICKSON, 2007; ERLIE; LYNN, 2007; FREDERICKSON et. el., 2003; FISHER, 1992; POLLIT, 1990).

Grande parte da discussão sobre a OGP se debruça justamente a verificar em que medida seu referencial normativo, com uma teoria do programa bem identificada em suas diretrizes, induz a inovações na governança e gestão que possibilitam uma "entrega" mais efetiva dos resultados propugnados por tais diretrizes (FREITAS; MACADAR; HENRIQSON, 2019; Hartog; Mulder, 2017; Bueno;BrelàZ; SAnlinas, 2016; LÉveillé; Timms, 2015; GURIN, 2014; DeOGIRIKAR, 2014; SHKABATUR, 2012; NOVECK, 2006).

Entende-se por teoria do programa a explicação analítica (explanação) que especifica produtos, resultados e, eventualmente, impactos de longo prazo de uma intervenção de política pública sobre um problema, partindo de uma explicação fundamentada desse mesmo problema, supondo suas causas essenciais e consequências principais (NEWCOMER et al., 2015; WEISS, 1998).

A "Parceria para Governo Aberto" (OGP), da qual o Brasil é membro cofundador, define governo aberto como uma agenda de promoção da transparência, da participação social e da colaboração cidadã no aprimoramento da governança e da gestão governamentais, com o fomento, sempre que possível, da utilização de novas tecnologias. A teoria do programa implícita a essas diretrizes é a de que governos mais abertos, por serem mais responsivos, tornam-se mais efetivos (PARCERIA PARA GOVERNO ABERTO, 2011).

A Carta Latino-americana de Governo Aberto, de 2016, aprovada durante a XVII Conferência Ibero-americana de Ministras e Ministros de Administração Pública e Reforma do Estado, relaciona a política de governo aberto a alterações na governança de políticas públicas, explicando em que consiste o governo aberto e suas consequências presumidas:

(...) um conjunto de mecanismos e estratégias que contribuem para a governança pública e bom governo com base nos pilares da transparência, da participação pública, da prestação de contas, da colaboração e da inovação, centradas no envolvimento de cidadãos no processo de tomada de decisão, assim como na formulação e na implementação de políticas públicas para 
fortalecer a democracia, a legitimidade da ação pública e o bem-estar coletivo. ${ }^{1}$ (CENTRO LATINOAMERICANO DE ADMINISTRACIÓN PARA El DESARROLlO, 2016, p. 5).

$\mathrm{Na}$ mesma linha, a Organização para a Cooperação e Desenvolvimento Econômico (OCDE) (2017) aposta na relação entre a adoção de princípios de governo aberto e melhorias na governança, na medida em que governo aberto, ao favorecer uma governança centrada no cidadão, reordena políticas e programas de modo a implementar práticas, instrumentos e ferramentas inovadoras e sustentáveis para promover transparência, melhor capacidade de resposta e maior responsabilização das organizações e dos agentes do Estado. Essas melhorias, viabilizadas por inovações de governo aberto e calcadas na maior participação e colaboração dos cidadãos, reforçariam o valor público da democracia com crescimento inclusivo.

A partir de 2011, o Plano de Ação Nacional sobre Governo Aberto (BRASIL, 2011) instou as organizações públicas de âmbito federal a desenvolverem iniciativas destinadas ao aprimoramento da governança pública. Portanto, a política pública de governo aberto orientou-se pelo princípio de que a descentralização, transparência, responsividade e controle social fomentam a geração de valor público.

Portanto, a teoria do programa da OGP indica compromissos que, transformados em diretrizes governamentais e implementados por órgãos governamentais, supostamente redundam em políticas e programas mais abertos, ou seja, mais transparentes, mais suscetíveis ao controle social, mais colaborativos. O resultado seria transformador e inovador para alcançar objetivos públicos de interesse da sociedade (STEIBEL, 2017), em termos da melhoria do acesso e da provisão de bens e serviços públicos de qualidade. Tal noção também se aproxima claramente do conceito de valor público, que tem assumido proeminência no debate mais recente sobre administração pública (MOORE, 2000).

A partir dessas referências, o esforço analítico aqui empreendido se dedica a buscar evidências que apontem em que medida tais mudanças de governança, inspiradas por princípios de governo aberto, efetivamente reforçam o valor público das políticas e programas.

\footnotetext{
${ }^{1} \mathrm{Na}$ formulação original: conjunto de mecanismos y estrategias que contribuye a la gobernanza pública y al buen gobierno, basado en los pilares de la transparencia, participación ciudadana, rendición de cuentas, colaboración e innovación, centrando e incluyendo a la ciudadanía en el proceso de toma de decisiones, así como en la formulación e implementación de políticas públicas, para fortalecer la democracia, la legitimidad de la acción pública y el bienestar colectivo.
} 
A metodologia empregada se valeu do estudo de caso, por razões que merecem ser esclarecidas. Em primeiro lugar, era preciso encontrar um caso em que houvesse de fato ocorrido mudanças na governança, implementadas a partir das diretrizes de governo aberto. Em segundo lugar, se fazia necessário encontrar um caso passível de observação em profundidade, capaz de apresentar registros tanto das mudanças ocorridas no âmbito da governança quanto dos possíveis produtos e resultados dessas mudanças. Além disso, era fundamental que a escolha recaísse sobre uma experiência em que esse processo de implementação de alterações da governança contasse com o devido tempo de maturação.

O estudo de caso se valeu da triangulação de métodos para uma análise em profundidade. A análise em profundidade é justamente a vantagem do estudo de caso (Borges, 2007; Yin, 2005; GeORge; BennetT, 2005; SÁ E Silva; LoPEZ; Pires, 2010). Para tanto, foram utilizadas a análise documental, principalmente das mudanças normativas que introduziram inovações afinadas com as diretrizes de governo aberto; a análise de dados (principalmente os da Ouvidoria-Geral do então Ministério do Desenvolvimento Social - MDS e do Sistema Eletrônico do Serviço de Informação ao Cidadão - e-Sic), pertinentes como evidências de algumas dessas mudanças e sua evolução; e, finalmente, entrevistas semiestruturadas.

Finalmente, o estudo de caso se mostrou adequado para que fossem realizadas entrevistas com dirigentes e gestores responsáveis por esse processo de implementação, de modo a entender a lógica que orientou a relação entre diretrizes de governo aberto e mudanças de governança. Foram realizadas 11 entrevistas semiestruturadas com dirigentes e gestores que estiveram diretamente envolvidos na gestão do programa Bolsa Família e conduziram ou experimentaram mudanças na governança de políticas públicas que se alinham ao conceito de governo aberto aqui exposto. Foi garantido o anonimato das fontes para assegurar que visões mais críticas sobre eventuais inconveniências e custos políticos, técnicos, administrativos e mesmo orçamentários desse processo de transformação na governança pudessem ser livremente expostas, sem constrangimentos.

Deve-se ressaltar que as entrevistas foram utilizadas como reforço à análise em profundidade do processo de implementação e de avaliação de resultados, e não como survey. Seu papel complementar era o de elucidar a lógica da motivação que levou à implementação de inovações de governo aberto; dos problemas enfrentados nessa implementação; e da maneira como esses problemas foram solucionados ou se mantiveram presentes. 
Foram controlados fatores de contexto básicos para o estudo de caso, ou seja, de que ele tivesse de fato sofrido um processo de intervenção (no caso, da política de governo aberto); que o processo tenha cumprido um prazo razoável de implementação; que houvesse dados quantitativos e qualitativos fidedignos e relevantes - portanto, que pudessem ser diretamente relacionados à intervenção realizada, seja confirmando ou refutando as premissas do referencial.

A análise pôde então debruçar-se sobre a pergunta de pesquisa, assim posta: havendo mudanças na governança, por meio da introdução de princípios de governo aberto, há sinais de aprimoramento do valor público de políticas ou programas governamentais? De que tipo e por quê?

\section{Governança como conceito e como agenda de políticas públicas}

Em janeiro de 2009, o recém empossado Presidente dos Estados Unidos da América, Barack Hussein Obama Junior, assinou o Memorandum on Transparency and Open Government, formalizando o uso da expressão governo aberto na diretiva endereçada aos chefes de departamento e agências do Estado ${ }^{2}$. A expressão estava envolta no contexto de construção de um governo cada vez mais transparente e colaborativo, como necessidade de reconquistar a confiança da sociedade civil.

Durante a $66^{\mathrm{a}}$ Assembleia Geral das Nações Unidas em Nova York, em setembro de 2011, os Estados Unidos da América e mais sete outros países (África do Sul, México, Brasil, Filipinas, Indonésia, Noruega e Reino Unido) publicaram a Declaração de Governo Aberto e criaram a OGP. A Declaração de Governo Aberto formalizou o compromisso desses oito países com princípios de transparência, prestação de contas, responsividade, participação cidadã, inovação e tecnologia, ao reconhecer que "as pessoas ao redor do mundo estão exigindo mais abertura no governo, reivindicando maior participação cívica nos assuntos públicos e buscando meios de tornar seus governos mais transparentes, receptivos, responsáveis e eficientes"(BRASIL, 2011, p. 1).

\footnotetext{
${ }^{2}$ No discurso, Obama se comprometia a "criar um nível de abertura sem precedentes no governo", por meio da transparência, participação social e colaboração. "A abertura fortalecerá nossa democracia e promoverá eficiência e efetividade no Governo", dizia o presidente, reafirmando os termos que consagraram a teoria do programa do OGP (USA, 2009, p. 3).
} 
No Brasil, os princípios de governo aberto foram inseridos oficialmente como agenda de políticas públicas a partir do Decreto s/n de 15 de setembro de 2011, que instituiu os planos de ação no âmbito da OGP. Com prazo de cumprimento de até dois anos, os planos de ação consistem em declarações voluntárias do Governo Federal de fomento a políticas públicas pautadas em princípios de governo aberto. Desde 2011, o Brasil já apresentou 4 Planos de Ação, com mais de 100 compromissos, caracterizados por suas diversas idiossincrasias e especificidades, tanto em suas formulações, quanto em seus graus de implementações e geração de valor público (MARIANI, 2019).

A instituição da Política Nacional de Governo Aberto ocorreu apenas em dezembro de 2019, com o Decreto $\mathrm{n}^{\mathrm{o}}$ 10.160/2019. A Política Nacional de Governo Aberto se embasa a partir de quatro diretrizes: a) aumento da disponibilidade de informações sobre as atividades governamentais; b) fomento à participação social nos processos decisórios; c) estímulo ao uso de novas tecnologias que fomentem a inovação, o fortalecimento da governança pública e o aumento da transparência e da participação social na gestão e na prestação de serviços públicos; d) aumento dos processos de transparência, de acesso à informação e da utilização de tecnologias que subsidiem esses processos (BRASIL, 2019).

Por fim, a criação do Comitê Interministerial de Governo Aberto, também pelo Decreto $n^{\circ}$ 10.160/2019, ao incluir em sua composição 11 Ministérios mais a Casa Civil e a Secretaria-Geral da Presidência da República, reforçou a preocupação do Governo Federal em desenvolver e implementar no âmbito ministerial a agenda de governo aberto nas políticas públicas.

\section{As transformações na governança orientadas pelo governo aberto}

Existe uma profusão de conceitos de governança, o que tem tornado o tema ao mesmo tempo intensamente discutido e confuso. A tal ponto que, conforme ressaltado por Frederickson (2007), se tornou tão ou mais importante do que conceituar governança dizer o que ela não é (FREDERICKSON, 2007, p. 293).

Frederickson (2007) propõe um conceito mais preciso de governança, com escopo mais bem delimitado. Compreende governança a partir da relação entre "jurisdição" - as regras de atribuição de poderes e obrigações a cada órgão do Estado -; organização (a maneira como essas organizações se estruturam); e burocracia - ou seja, quem maneja 
tais regras dentro das organizações. De forma muito similar, Lynn, Heinrich e Hill (2001, p. 7) definem governança como o regime de regras (leis, regras ou decisões) da atuação das organizações e de seus burocratas para a provisão de bens e serviços.

Na mesma linha de Frederickson (2007), Lassance (2015) estabelece um conceito de governança como a distribuição de competências e atribuições dentro das organizações do Estado. Governança é a definição de "quem pode decidir sobre o quê" e "quem faz o quê" (LASSANCE, 2015). O conceito, de escopo mais minimalista, tem a vantagem não só de se mostrar operacionalizável, como de manter equidistância - evitando confusões - do conceito de gestão.

Essa precaução conceitual de garantir um conceito mais preciso e operacionalizável não aparece plenamente na conceituação de organismos internacionais e órgãos de controle. O Banco Mundial, por exemplo, que é precursor da ideia e da agenda de governança pública, fala em governança de maneira bastante difusa, enquanto "a maneira pela qual o poder é exercido na gestão dos recursos econômicos e sociais de um país para o desenvolvimento"3 (WORLD BANK, 1992, p. 3).

No Brasil, o conceito prescrito pelo Tribunal de Contas da União (TCU) e adotado pela política de governança do Governo Federal (BRASIL, 2017) é igualmente hipertrofiado, correspondendo a "mecanismos de liderança, estratégia e controle postos em prática para avaliar, direcionar e monitorar a atuação da gestão, com vistas à condução de políticas públicas e à prestação de serviços de interesse da sociedade" (TRIBUNAL DE CONTAS DA UNIÃO, 2013, p. 26).

De todo modo, a atuação prescritiva impulsionada pelo TCU, incorporada também como diretriz pela Presidência da República desde a política de governança, de 2017, passou a ser adotada por vários órgãos federais como base para a promoção de alterações de governança. Várias dessas mudanças se alinhavam aos preceitos do governo aberto, na medida em que almejavam aprimorar a atuação dos agentes públicos segundo requisitos de transparência, incentivo à participação e abertura de canais de colaboração com cidadãs e cidadãos.

A agenda protagonizada pelo TCU teve como documento inicial o Referencial Básico de Governança, os Dez Passos para a Boa Governança do TCU, que propôs

\footnotetext{
${ }^{3} \mathrm{Na}$ formulação original: "is the manner in which power is exercised in the management of a country's economic and social resources for development."
} 
mecanismos para estimular: i) a escolha de líderes competentes e a avaliação de seus desempenhos; ii) que se lidere com ética e que se combatam desvios; iii) que se estabeleça um "sistema de governança com poderes de decisão balanceados e funções críticas segregadas"; iv) um modelo de gestão da estratégia que assegure seu monitoramento e avaliação; v) uma estratégia considerando as necessidades das partes interessadas; vi) o estabelecimento de metas que deleguem poder e recursos para alcançá-las; vii) mecanismos de coordenação de ações com outras organizações; viii) o gerenciamento de riscos que institua os mecanismos de controle interno necessários; ix) o exercício da função de auditoria interna independente e que adicione valor à organização; x) o estabelecimento de diretrizes de transparência e sistema de prestação de contas e responsabilização (BRASIL, 2014).

Em seguida, o Acórdão ${ }^{\circ}$ 1273/2015 do TCU recomendou à Casa Civil, ao Conselho Nacional de Justiça e ao Conselho Nacional do Ministério Público que elaborassem modelo de governança a partir de três linhas centrais: a) liderança; b) estratégia; c) controle. Recomendou também que o Congresso Nacional avaliasse as orientações do acórdão para pautar discussão de criação de ato normativo que estabelecesse boas práticas de governança voltadas para a melhoria do desempenho de órgãos e entidades da administração pública direta e indireta, bem como dos demais Poderes na esfera federal. Publicada em 10 de maio de 2016, a Instrução Normativa $n^{o}$ 001 Conjunta do Ministério do Planejamento e do Ministério da Transparência e Controladoria-Geral da União (CGU) dispôs sobre o controle interno, a gestão de risco e a governança no âmbito do Poder Executivo federal.

Pela IN no 001/2016, governança foi apresentada como a "combinação de processos e estruturas implantadas pela alta administração, para informar, dirigir, administrar e monitorar as atividades da organização, com o intuito de alcançar os seus objetivos" (BRASIL, 2016). O citado decreto da política de governança reincidiu nesse conceito apresentado pela IN 001/2016 (BRASIL, 2017). Além de alinhado a princípios de governo aberto, o decreto trazia em suas entrelinhas uma noção de valor público, na medida em que propugnava, em sua exposição de motivos, uma atuação orientada em prol do cidadão.

Gerar valor público, como compreendido por Moore (2000), consiste no impacto sobre a qualidade do relacionamento com as cidadãs e cidadãos e as organizações da sociedade. Na mesma linha, Mariani (2019) defende que gerar valor público é ofertar 
respostas efetivas a necessidades e demandas, com resultados que modifiquem aspectos da sociedade.

A essência do conceito de governança no setor público, trazido pela $\mathrm{IN}^{\circ}$ 001/2016 e pelas quatro diretrizes de governo aberto instituídas pela Política Nacional de Governo Aberto, pode ser claramente percebida no aprimoramento da geração de valor público pelo programa Bolsa Família ao longo dos anos. Assim, a necessidade de respostas efetivas e úteis às necessidades e às demandas da sociedade fizeram com que o programa Bolsa Família construísse seu referencial próprio de governança para a geração de valor (MARIANI, 2019).

\section{A construção de um referencial próprio de governança do Bolsa Família}

Um aspecto importante ao Bolsa Família, enquanto estudo de caso, é que o programa, criado em 2003, passou por um processo de construção de seu referencial próprio de governança, com preocupações quanto à transparência, participação e colaboração, anteriormente à adesão do Brasil à iniciativa de governo aberto e ao estabelecimento dos referenciais normativos de governança do TCU e do Governo Federal. A genealogia desse processo pode ser mais bem compreendida com uma visão do contexto de criação do programa.

Do ponto de vista de diagnóstico estratégico, quando foi lançado, o programa apresentava elementos preocupantes, como:

[...] pulverização de recursos; elevado custo administrativo; superposição de público-alvo; competição entre ministérios; ausência de coordenação e de perspectiva intersetorial no combate à pobreza e à desigualdade; descaso pela existência de programas similares nos estados e municípios; ausência de reflexão sobre "portas de saída"; fragilidades e incompreensões acerca do cadastro; desconsideração com estados e municípios na gestão das políticas públicas" (FONSECA; ROQUETE, 2005, p. 14).

Induzido pela dinâmica do programa e pela pressão social, o programa Bolsa Família, muitas vezes de forma intuitiva, outras vezes, alinhada com diretrizes governamentais, forjou seu referencial próprio de governança ao longo dos anos, a partir de elementos coincidentes com os de governo aberto. Como identificado pelo Entrevistado 9, desde sua base de implementação, o programa buscou a inserção de elementos de transparência, participação social e inovação, os quais foram sendo aprimorados a cada ciclo de gestão. 
Para a governança do programa Bolsa Família se exigia uma complexa arquitetura institucional de supervisão da gestão, o que demandava o desafio de uma boa articulação do Governo Federal com os outros entes federativos, que foi possível por meio de inovações administrativas, como, por exemplo, a criação do Índice de Gestão Descentralizada (IGD. Assim, a partir de uma gestão descentralizada em rede, o programa inovou com a inclusão efetiva de estados e municípios na gestão pública com ações coordenadas que permitiram a construção de uma definição sistêmica de controle e acompanhamento das condicionalidades do programa (MARIANI, 2019).

O aprimoramento do desenho do Cadastro Único (CadÚnico) representou inovação tecnológica que viabilizou a consolidação de informações em base única. Para o Entrevistado 2, o CadÚnico permitiu que cada um dos municípios brasileiros pudesse "conhecer as famílias e identificar suas vulnerabilidades", sendo um mecanismo de transparência e um instrumento de planejamento inovador que auxilia a governança da política para a realidade da população.

Assim, o valor público gerado pelos elementos de inovação do programa pode ser associado à eficiência na alocação de recursos, uma vez que os governos locais, por estarem mais informados sobre as necessidades específicas da população, puderam controlar de forma mais efetiva a chamada "porta de entrada" do programa, por meio da identificação de famílias pelo CadÚnico.

Para o Entrevistado 1, é possível vislumbrar que, tendo como base a governança de descentralização das políticas sociais, em um país com estrutura federativa como a do Brasil, a ausência de instrumentos inovadores de gestão poderia ser fator que contribuiria para "o insucesso da proposta". O Entrevistado 9 conclui que o programa Bolsa Família “inovou em todas as áreas, seja na ideia, no formato, na maneira de implementação, na escala, na tecnologia de pagamento dos benefícios e na defesa da mulher como beneficiária preferencial do programa”. Todos esses elementos citados representam características do que se pode entender como valor público.

Se por um lado podemos considerar que elementos de inovação surgiram na governança do programa Bolsa Família pela própria dinâmica de implementação do programa, o mesmo não pode ser atestado sobre o fomento à participação social, que teve de ser impulsionado por normativos do Governo Federal.

Conforme ressaltado pelo Entrevistado 6, uma das maiores debilidades que existia na governança era "a fragilidade da participação social". Apesar de no desenho 
institucional ter sido estabelecido que a gestão seria pública e governamental e que o controle e a participação social seriam realizados, em âmbito local, por um conselho ou comitê (BRASIL, 2015), a fase inicial de implantação ficou marcada pelo "vazio normativo quanto às ações desse controle".

Para o Entrevistado 3, a institucionalização do controle social se constitui na época um desafio não só para o Bolsa Família, mas para as políticas públicas brasileiras como um todo, considerando a fragilidade de mobilização social e a "pouca tradição democrática do poder público". De fato, apenas houve a definição legal das instâncias responsáveis pelo acompanhamento do programa Bolsa Família com o Decreto no 5.209 de regulamentação e a Portaria n. $^{\circ}$ 660, em setembro e novembro de 2004, respectivamente.

O Entrevistado 4, ao analisar o diagrama de participação social elaborado pela Associação Internacional para a Participação Pública (IAP2), tece reflexão crítica acerca do grau de maturação da participação social no programa Bolsa Família e da relação entre governo e sociedade civil em um plano mais horizontalizado.

O desafio da governança da participação cidadã se reveste de complexidade ainda maior a partir da instituição do Decreto $\mathrm{n}^{\mathrm{o}} 7.332 / 2010$, em que os municípios ficaram obrigados a destinar pelo menos $3 \%$ dos recursos recebidos pelo IGD ao colegiado que acompanha as ações do programa e do CadÚnico para execução do controle social.

Diante desse contexto, podem surgir questionamentos quanto à dimensão efetiva do valor público gerado pelas alterações na governança do programa a partir da participação social e da busca por uma relação de colaboração representada pela coparticipação e corresponsabilidade. Contudo, melhorias na geração de valor público associadas a uma maior transparência, participação e colaboração na interface com cidadãs e cidadãos podem demandar um tempo de maturação maior para que apresentem resultados. Afinal, essas mudanças na maioria das vezes não estão relacionadas a entregas de benefícios imediatos, mas a alterações incrementais, de caráter organizacional, procedimental e até cultural, cuja relevância e escala dependem de interações e aprendizados mútuos e que se mantenham presentes por um médio ou longo prazos.

No entanto, mudanças de governança que possibilitaram, por exemplo, a criação e o gerenciamento do CadÚnico, com aprimoramentos paulatinos, ao mesmo tempo em que permitiram ganhos de transparência e acesso às informações públicas, com claras e imediatas melhorias na geração de valor público, tiveram resultados impactantes e 
imediatos sobretudo por estarem diretamente ligadas a uma ferramenta gerencial primordial à própria implementação do programa. $\mathrm{O}$ programa nasceu com atributos de transparência pública para que sua própria implementação se viabilizasse em escala e de modo acelerado. Além disso, o amplo debate e intensa exposição crítica do programa tornou o requisito de transparência uma resposta necessária à sua sobrevivência e um anteparo à sua imagem pública.

Segundo o Entrevistado 11, em 2019, por exemplo, as secretarias responsáveis pelo Bolsa Família e CadÚnico permaneceram como as mais demandadas pelos canais de atendimento ao público, sendo as demandas associadas com a situação do benefício (bloqueio, liberação, cancelamento e suspensão) e com a atualização cadastral do CadÚnico.

O Sistema Eletrônico do Serviço de Informação ao Cidadão (e-Sic) do MDS só foi criado a partir de maio de 2015, mas, assim que entrou em operação, o quantitativo de demandas direcionadas à Secretaria Nacional de Renda de Cidadania (Senarc), unidade responsável pela gestão do Programa Bolsa Família, aumentou de 55 pedidos por ano, em 2016, para 96 pedidos em 2019. Como identificado pelo Entrevistado 9, a maioria desses pedidos de informação era oriunda de pesquisas acadêmicas e de meios de comunicação.

Por sua vez, a interação do público com a Senarc, por meio da Ouvidoria do MDS, passou de 6.828, para 22.802 em 2019, portanto, 333\% a mais (segundo o Relatório de Atendimento da Ouvidoria-Geral do Ministério da Cidadania) (BRASIL, 2020). Parte da explicação dessa expansão decorre certamente do fato de que o programa também se expandiu, mas a uma taxa menor. O número de beneficiários do Bolsa Família era de 6 milhões de famílias em 2004, passando a 13,3 milhões de famílias em 2017 (FERREIRA; OSÓRIO; PAIVA; SOARES, 2019) e tendo-se mantido quase nesse mesmo patamar até 2019 (13,5 milhões), ou seja, um crescimento pouco acima do dobro (225\%).

A variação tampouco pode ser atribuída a uma intensificação de problemas decorrentes de cadastramento ou por outros fatores, tendo em vista que o crescimento da interface do público via Ouvidoria se manteve consistente e pouco sujeito a grandes oscilações. Supondo que a ocorrência de problemas e de situações operacionais próprias do programa, como o recadastramento, são constantes, essa variação do acesso a informações por meio da Ouvidoria e também do e-Sic pode ser atribuída a um maior conhecimento e à confiança nesses canais. 
A arquitetura de governança do Bolsa Família desenhou os procedimentos gerenciais de transparência do programa tanto em termos da transparência passiva quanto da transparência ativa. No entanto, como ressalta o Entrevistado 10, a partir da instituição da Lei de Acesso à Informação (BRASIL, 2011), a agenda da transparência passiva do programa se tornou "meteórica".

Como também esclarece o Entrevistado 8, o Plano de Dados Abertos (PDA) "trouxe mais transparência quanto ao planejamento da abertura de dados". O Plano de Dados Abertos 2017/2019 do extinto Ministério do Desenvolvimento Social, responsável pela gestão do programa Bolsa Família, estabeleceu diretrizes para nortear a organização e a revisão de dados em transparência ativa da pasta. Um estudo que embasou a construção do PDA identificou que a maioria dos pedidos de acesso à informação do órgão, 60\% dos pedidos, eram referentes ao programa Bolsa Família (MinISTÉRIO DO DESENVOLVIMENTO SOCIAL, 2017).

Para o Entrevistado 7, "houve um grande avanço na transparência ativa do programa", pois a política de dados abertos permitiu o livre acesso, o uso e o compartilhamento de informações que antes eram objeto de transparência passiva, como série histórica de indicadores dos resultados governamentais, quantidade de famílias atendidas, quantidade de benefícios básicos e variáveis, valor total do repasse, nome do beneficiário, data do saque e, principalmente, os valores dos saques.

Fica patente uma relação entre transparência passiva e ativa, percebida por dirigentes e gestores, que buscaram transformar o crescimento da solicitação por informações fornecidas (transparência passiva) em dados abertos e estruturados para a consulta (transparência ativa). Esse salto rumo à transparência viabilizou uma redução dos custos operacionais de resposta, que demandam tempo de servidores em consultas e formulação de respostas, além de também atender a imposições normativas dos controles interno e externo que sistematicamente são endereçadas a dirigentes e gestores.

No Bolsa Família, diversos dados e informações sobre o programa tornaram-se disponíveis em transparência ativa graças à construção paulatina de um conjunto de ferramentas informatizadas com a consultoria técnica da Secretaria de Avaliação e Gestão da Informação (Sagi) do então MDS (hoje Ministério da Cidadania - MC). Para o Entrevistado 2, a disponibilização da base não desidentificada do CadÚnico, com marcação dos beneficiários em microdados no formato ".csv", com 30 variáveis desidentificadas referentes a famílias e 34 referentes a pessoas, fomentou mais pesquisas 
sobre o Bolsa Família. Propiciar ou mesmo estimular pesquisas e análises, sejam as realizadas internamente ou por pesquisadores de organizações independentes (universidades, institutos e centros de pesquisa, think tanks), pode também ser considerado como um recurso de transparência ativa com impacto sobre o valor público dos programas governamentais.

A propósito, o próprio aprimoramento das atribuições da Sagi como uma unidade caracterizada pela produção de informação sistematizada e pela elaboração de insumos para o aprimoramento da gestão em si foi uma das grandes alterações na governança do Ministério e que teve importância crucial para o seu principal programa.

Igualmente o reforço à área de governança da tecnologia da informação. Ao longo dos anos, a Sagi desenvolveu diversas ferramentas de visualização de dados, sendo responsável por, em diversas granularidades, armazenar e organizar informações de diversos programas, ações e projetos, "desde informações pessoais até agregados por região e país. Em picos de acesso, as ferramentas da Sagi têm cerca de 1,5 milhão de consultas em um único dia. Mais de cem países acessam esses dados regularmente" (Ministério do DESENVOLVIMENTO SOCIAL, 2015, p. 68).

Após a abertura da base de dados, houve registro pela Sagi de quase 1000 downloads mensais realizados. O Entrevistado 2 sugere que esse "sucesso na quantidade de downloads" proporciona um recurso de transparência ativa por possibilitar, com recortes por período e por região, dados atualizados sobre a pirâmide etária dos beneficiários, a distribuição geográfica, o valor médio do benefício, o acompanhamento de condicionalidades e a quantidade de benefícios concedidos e bloqueados.

Outro aspecto, ressaltado pelo Entrevistado 8, é que "a abertura de dados pode ensejar parcerias, análises, trabalhos, aplicativos e outras soluções”. Para ele, "o simples olhar diferenciado do cidadão", na maioria das vezes, desprovido dos vieses que podem eventualmente acometer os servidores envolvidos com o programa, pode fazer com que qualquer base de dados governamental tenha potencial para produzir valor público para o país. Outro aspecto interessante do cruzamento de dados, como lembrado pelo Entrevistado 2, é que ele permite também "descobertas surpreendentes", como a de beneficiários do Bolsa Família entre os medalhistas da Olimpíada de Matemática de Escolas Públicas (OBMEP) (MINISTÉRIO DO DESENVOLVIMENTO SOCIAL, 2018).

Para o Entrevistado 1, com o acesso aos dados públicos, o monitoramento pelos cidadãos fica mais tempestivo, o que, de certa forma, "pressiona os governos a serem 
mais responsivos". Ao viabilizar constantes avaliações, monitoramentos e aprimoramentos da política pública, a governança do programa instigou o fortalecimento da instituição, da cidadania, do controle social e do combate à corrupção, se constituindo não apenas como instrumento de gerenciamento de riscos estratégicos e mecanismo de gestão e controle, mas também como uma ponte de conexão entre governo e sociedade.

\section{Conclusões}

A partir do estudo de caso do programa Bolsa Família apresentado, foi possível compreender em que medida a introdução de princípios de governo aberto, ao promover mudanças na governança da política pública, favoreceu a geração de valor público. A inovação administrativa a partir de uma gestão descentralizada em rede, o fomento da participação social, com a implementação dos conselhos, e o aumento dos processos de transparência e de inovação, com o aprimoramento do desenho do CadÚnico, permitiram que o programa ganhasse mais legitimidade e suporte e reforço à sua operacionalidade.

O programa Bolsa Família, que abrange mais de 19 milhões de famílias, se consolidou como maior programa de transferência condicionada de renda do mundo e se tornou referência na geração de valor público no contexto da proteção social, em aspectos aqui evidenciados. Os problemas principais experimentados pelo programa consistem na existência de pessoas que recebem indevidamente recursos do Bolsa Família (problema, porém, cuja ocorrência sempre foi residual) e, de maior relevância, o fato de que muitas outras pessoas, tendo o direito a receber tais recursos, ainda aguardam na fila para terem seus direitos reconhecidos e receberem os benefícios correspondentes. No entanto, mesmo a ocorrência de tais problemas ocasionais tem contribuído para reforçar a legitimidade e o valor público do programa, e não ao questionamento de sua importância.

Este estudo demonstrou que o Bolsa Família, mais do que atender a normativos prescritivos e adotar uma governança orientada por padrões genéricos, construiu seu próprio modelo (ou referencial) de governança. Alguns aspectos cruciais desse modelo coincidiam com princípios e diretrizes que só se tornariam explícitos bem posteriormente, a partir da iniciativa de governo aberto e de recomendações dos referenciais e normativos de governança do TCU e da Presidência da República.

Essas coincidências foram na verdade motivadas por uma governança do programa que tinha a necessidade prática de encontrar soluções gerenciais que trouxeram 
agilidade e facilidades operacionais à sua implementação e prestação de contas. Essas soluções, materializadas na forma de algumas ferramentas de política, como o CadÚnico, os canais de atendimento da Ouvidoria-Geral e avaliações do programa, feitas internamente ou por pesquisadores independentes, foram anteriores ao aparecimento de referenciais mais claros e mandatórios sobre governo aberto e governança pública. Outros, como a disponibilização de dados abertos, decorreram sobretudo da Lei de Acesso à Informação, de 2011.

Todas essas ferramentas reforçaram o valor público do programa, permitindo ao escrutínio público uma superexposição de informações sobre o Bolsa Família. Isso não apenas atendeu a uma ação dos órgãos de controle, como e serviu de resposta a críticas que foram feitas ao programa, desde seu surgimento, em 2003. Elas foram sobretudo ferramentas que reduziram custos gerenciais de operação e otimizaram o tempo de dirigentes e gestores, que rotineiramente se viam às voltas com demandas por informação que precisavam ser respondidas com algum grau de urgência.

Pode-se supor que, de um modo geral, em programas implementados em larga escala, com governança descentralizada, sujeitos a uma intensa fiscalização e cobrança por parte dos órgãos de controle, com grande magnitude de recursos envolvidos e alta sensibilidade de seu público alvo, como é o caso do Bolsa Família, as ferramentas de transparência ativa não apenas sustentam a legitimidade e valor público do programa, como são essenciais à agilidade de suas respostas de curto prazo, e isso reforça suas chances de sobrevivência no longo prazo.

Evidenciou-se também uma relação entre transparência passiva e ativa, na medida em que dirigentes e gestores assoberbados com solicitações por informações (transparência passiva) estruturaram plataformas de dados abertos, patrocinaram ou facilitaram pesquisas, publicações e recursos para a consulta, portanto, migraram para a transparência ativa. Esse salto reduziu custos operacionais e a demanda por tempo de servidores que puderam concentrar seu foco sobre o comando do programa.

Em suma, ao invés de responder a um modelo genérico de governança, a governança do programa criou incentivos políticos e institucionais capazes de estruturar respostas mais ágeis a problemas complexos, críticos e de grande magnitude, de forma antecipada e proativa. Tudo isso em um modelo específico de governança. Ainda assim, as diretrizes centrais dos governos, expedidas ex-post, se mostraram essenciais para que outros avanços se tornassem mais céleres. 
Conclui-se também que a relação entre governo aberto, governança e valor público de um programa não é dada a priori, a não ser teoricamente, e só pode de fato se efetivar se construída politicamente a partir de uma estratégia deliberada e inteligente de dirigentes e gestores públicos. Afinal, os "louros" da transparência demandam um tempo de maturação maior do que aquele relacionado à entrega de resultados. Porém, a simples entrega de resultados, sem que haja dados de monitoramento e processos sistemáticos de avaliação capazes de produzir evidências que sejam categóricas, adequadas a um debate público cada vez mais agressivo em muitos aspectos, pode fazer com que o programa se torne alvo fácil de ataques difíceis de serem plenamente defendidos pelos que estão à frente do programa.

Instrumentos de transparência se tornam mais efetivos se desenhados como ferramentas associados à dinâmica gerencial dos programas. A dimensão organizacional e cultural desses instrumentos, cuja maturação é de médio e longo prazo, não tem um fim em si mesma. Ganhos de transparência e de legitimidade, na forma de um aumento do valor público, dependem de alguma conexão e facilidade para a governança e a gestão. $\mathrm{O}$ objetivo é desincumbir a governança de problemas na exposição crítica do programa, robustecendo sua capacidade de resposta e permitindo que o uso de dados abertos em larga escala ("big data") possa fornecer informações de monitoramento que orientem ajustes pontuais necessários e a correção de possíveis problemas antes que eles se tornem críticos.

Os sucessivos redesenhos organizacionais do então MDS foram essenciais para produzir as citadas ferramentas que impulsionam uma maior transparência pública do programa. Também facilitaram a transição da transparência passiva para a ativa e maior colaboração com agentes externos interessados em investigar e expor avanços e gargalos do programa. Avanços que fortaleceram ainda mais a imagem e o valor público do programa. Gargalos que, mapeados, foram objeto de alterações corretivas importantes.

Por fim, conclui-se que, para um programa tão obcecado por "portas" (de entrada e saída), as transformações na governança e a construção de ferramentas de governo aberto deram ao programa verdadeiras "janelas". Elas permitiram que as entregas de benefícios feitas pelo Bolsa Família fossem melhor iluminadas. Mesmo a crítica contundente e infundada ao programa, confrontada com dados da transparência pública, acabaram por reforçar sua imagem e permitir a longevidade do Bolsa Família. 


\section{Referências}

BORGES, André. Desenvolvendo argumentos teóricos a partir de estudos de caso: o debate recente em torno da pesquisa históricocomparativa. $B I B$, São Paulo, n. 63 , p. $45-59,1^{\circ}$ semestre de 2007. Disponível em: http://snh2007.anpuh.org/resources/content/anai s/Andre\%20Borges.pdf Acesso em: 11 set. 2020.

BRASIL. Decreto 10.160, de 9 de dezembro de 2019. Institui a Política Nacional de Governo Aberto e o Comitê Interministerial de Governo Aberto. Disponível em:

http://www.planalto.gov.br/CCIVIL_03/Ato20 $19-$

2022/2019/Decreto/D10160.htm\#: :text=1\%C2 \%BA\%20Fica\%20institu\%C3\%ADda\%20a\%20 Pol\%C3\%ADtica,melhoria\%20na\%20presta\%C 3\%A7\%C3\%A3o\%20de\%20servi\%C3\%A7os

Acesso em: 15 set. 2020

BRASIL. Decreto $n^{\circ} 9.203$, de 22 de novembro de 2017. Dispõe sobre a política de governança da administração pública federal direta, autárquica e fundacional. Disponível em: http://www.planalto.gov.br/ccivil_03/Ato2015 -2018/2017/Decreto/D9203.htm Acesso em: 15 set. 2020.

BRASIL. Decreto $n^{\circ} 5.209$, de 17 de setembro de 2004. Regulamenta a Lei $\mathrm{n}^{\mathbf{0}} 10.836$, de 9 de janeiro de 2004, que cria o Programa Bolsa Família, e dá outras providências. Disponível em:

http://www.planalto.gov.br/ccivil_03/_Ato2004

2006/2004/Decreto/D5209.htm\#: :text=Regula menta\%20a\%20Lei\%20no,que\%20lhe\%20conf ere\%20o\%20art. Acesso em: 15 set. 2020.

BRASIL. Decreto $s / n^{o}$, de 15 de setembro de 2011. Institui o Plano de Ação Nacional sobre Governo Aberto e dá outras providências. Disponível em:

http://www.planalto.gov.br/ccivil_03/_ato20112014/2011/dsn/dsn13117.htm Acesso em: 15 set. 2020.

BRASIL. Instrução Normativa Conjunta $n^{\circ} 1$ do Ministério do Planejamento e do Ministério da Transparência e Controladoria-Geral da União. Dispõe sobre controles internos, gestão de riscos e governança no âmbito do Poder Executivo federal. Disponível em: https://www.in.gov.br/materia//asset publisher/Kujrw0TZC2Mb/content/id/21 519355/do1-2016-05-11-instrucao-normativa- conjunta-n-1-de-10-de-maio-de-2016-21519197 Acesso em: 15 set. 2020.

BRASIL. Portaria $n^{\circ}$ 660, de 11 de novembro de 2004. Disponível em:

http://www.mds.gov.br/webarquivos/legislacao/ bolsa familia/_doc/portarias/2004/Portaria\%20 GM\%20MDS\%20660\%2011-11-04.pdf Acesso em: 15 set. 2020 .

BRASIL. Projeto de Lei (PL) $n .^{\circ} 9.163$, de 23 de novembro de 2017. Dispõe sobre a política de governança da administração pública federal direta, autárquica e fundacional. Disponível em: https://www.camara.leg.br/proposicoesWeb/fich adetramitacao?idProposicao $=2163153$ Acesso em: 15 set. 2020

BRASIL, Ministério da Cidadania. Relatório da Central de Relacionamento da Ouvidoria-Geral do Ministério da Cidadania. Brasília: Ministério da Cidadania, 2020.

BuEnO, R. L.; BrelàZ, G.; SAlinAS, N. Administração pública brasileira no século 21: seis grandes desafios. Revista do Serviço Público, v. 67, p. 7-28, 2016. https://doi.org/10.21874/rsp.v67i0.1152

CAStro, Henrique Carlos de Oliveira de; WALTER, Maria Inez Machado Telles; SANTANA, Cora Maria Bender de; StePhAnOU, Michelle Conceição. Percepções sobre o Programa Bolsa Família na sociedade brasileira. Opin. Publica [online] v. 15, n. 2, p. 333-355, 2009.

CENTRO LATINOAMERICANO DE ADMINISTRACIÓN PARA EL DESARROLLO (CLAD). Carta Iberoamericana de Gobierno Abierto. Conferencia Iberoamericana de Ministras y Ministros de Administración Pública y Reforma del Estado Bogotá, 17., 7 y 8 de julio de 2016, Colombia. Anais...Bogotá: Clad, 2016. Disponível em <https://www.clad.org/images/declaraciones/CI GA-Octubre-2016.pdf > Acess 15 set 2019.

CROSS, L. Harold. The people's right to know: legal access to public records and proceedings. New York: Columbia University Press, 1959. Second Supplement.

DEOGIRIKAR, Anjelika. The impact of Open Government on innovation: does government transparency drive innovation? Washington: 
Georgetown University, 2014. Tese de Doutorado.

DuTTON, William. Networking distributed public expertise: strategies for citizen sourcing advice to government. Washington DC: Institute for Defense Analyses, 2011.

ERLIE, Ewan; LYNN JR., Laurence E.; POLLITT, Christopher. The Oxford Handbook of public management. Oxford: Oxford University Press, 2007.

EUROPEAN UNION. Creating value through Open Data. SMART 2014/4072, 2015.

FERRAREZI, E.; AMORIM, S. N. Concurso Inovação na Gestão Pública Federal: análise de uma trajetória (1996-2006). Brasília: Enap, 2007. p. 1-53. (Cadernos Enap, n. 32).

FISCHER, Tania. Poder local: um tema em análise. Rev. Adm. Pública, v. 26, n. 4, p. 105113,1992

FERREIRA, Pedro H. G.; OsÓRIO, Rafael Guerreiro; PAIVA, Luis Henrique; SOARES, Sergei. Os efeitos do programa bolsa família sobre a pobreza e a desigualdade: um balanço dos primeiros quinze anos. Texto para Discussão $\mathrm{n}^{\circ}$ 2499. Rio de Janeiro: Ipea, agosto de 2019. Disponível em: https://www.ipea.gov.br/portal/images/stories/P DFs/TDs/td_2499.pdf Acesso em: 11 set. 2020.

FREDERICKSON, H. George. Whatever happened to public administration? Governance, governance everywhere. In: FERLIE, Ewan; LYNN JR., Laurence E.; POLLITT, Christopher. The Oxford Handbook of Public Management. Oxford: Oxford University Press, 2007.

FREDERICKSON, H. George et al. The public administration theory primer. Boulder: Taylor \& Francis, 2003.

Freitas, J.; Macadar, M. A; HenriQson, E. A participação eletrônica no Uruguai, Chile e Colômbia a partir da teoria da ação comunicativa. Revista do Serviço Público, v., 70, n. 2, p. 239-266, 2019. Disponível em: https://doi.org/10.21874/rsp.v70i2.3238

George, A.; Bennett, A. Case studies and theory development in the social sciences. London/ Cambridge: MIT Press, 2005.

GURIN, Joel. Open governments, open data: a new lever for transparency, citizen engagement, and economic growth. SAIS Review of International Affairs, v. 34, n. 1, p. 71-82, 2014.

HARTOG, Martijn; Mulder, Bert. Accountable and responsible disclosure of financial open government data: open spending initiatives enhancing civic engagement. In: INTERNATIONAL CONFERENCE ICT, SOCIETY AND HUMAN BEINGS. 2017. p. 127-133.

Hilgers, Dennis and PILler, F. T. A government 2.0: fostering public sector rethinking by open innovation. Innovation Management, v. 1, n. 2. p. 1-8, 2011.

LASSANCE, Antonio. Governança e gestão: uma radiografia dos gargalos do Estado brasileiro. In: Boletim de Análise Político-Institucional $n^{\circ} 8$, Brasília: julho - dezembro 2015. p. 39-44.

LÉVEILLÉ, Valerie; TIMMS, Katherine. Through a records management lens: creating a framework for trust in Open Government and Open Government Information. Canadian Journal of Information and Library Science, v. 39, n. 2, p. 154-190, 2015. Disponível em: https://muse.jhu.edu/article/590939/pdf?casa_to $\mathrm{ken}=\mathrm{a}-$

mq_vHuSvIAAAAA:2UNQVo9ioyvnR55FSL mrEHpjvK1cGcKy3fweBPijkYIrVnDyAX4u8THoGyKNQgeXOy BwLnd Acesso em: 11 set. 2020.

LOPEZ, Felix Garcia. Accountability e controle social na administração pública federal. In: SÁ E Silva, Fabio de; LOPEZ, Felix Garcia; PIRES, Roberto Rocha C. (Orgs.). Estado, instituições e democracia. Volume 2: democracia. Brasília: Ipea, 2010. p. 185-210.

LYNN, L. E. JR; HENRICH, C.; HILL, C.J. Improving governance: a new logic for empirical research. Washington, DC: Georgetown University Press, 2001.

LYNN, L. E. JR; HENRICH, C. Governance and performance: new perspectives. Washington, DC: Georgetown University Press, 2000.

MaLdonado, N. The World Bank's evolving concept of good governance and its impact on human rights. Stockholm: Sweden, 2001.

MARIANI, C. B. Governo aberto e a governança do Programa Bolsa Família. Brasília: Ipea, 2019.

MARQUES, Eduardo Cesar. Government, political actors and governance in urban policies 
in Brazil and São Paulo: concepts for a future research agenda. Brazilian Political Science Review, São Paulo, v. 7, n. 3, p. 8-35, 2013.

MCCUBBInS, MATHEW D.; SCHWARTZ, THOMAS. Congressional oversight overlooked: police patrols versus fire alarms. American Journal of Political Science, v. 28, p. 16-79, 1984.

MinistéRIO DO DESENVOLVIMENTO SOCIAL (MDS). Caderno de Estudos: Desenvolvimento Social em Debate, n. 30. Brasília, 2018.

MinistérIO DO DESENVOLVIMENTO SOCIAL (MDS). Plano de Dados Abertos, 2017-2019. Brasília, 2017.

MINISTÉRIO DO DESENVOLVIMENTO SOCIAL (MDS). Relatório de Gestão, exercício 2018. Brasília, 2019.

Ministério DO DESENVOLVIMENTO SOCIAL (MDS). Sagi, Informação e Conhecimento para Políticas de Desenvolvimento Social. Brasília: Sagi, 2015.

MoORE, D. B. Development Discourse as Hegemony: Toward an Ideological History 1945-1995. In: MoORE, David B.; SCHMITZ, Gerald J. (Eds.). Debating development discourse: institutional and popular perspectives. London: Macmillan Press, 1995.

MoORE, H. Mark. Creating public value: strategic management in government. Cambridge Massachusetts. London, England. Fifth Edition, 2000.

NEWCOMER, Kathryn E.; HATRY, Harry P.; WHOLEY, Joseph S. Handbook of practical program evaluation. Hoboken: John Wiley \& Sons, 2015.

Noveck, Beth Simone. Peer to patent: collective intelligence, open review, and patent reform. Harv. JL \& Tech., v. 20, p. 123, 2006.

ORGANIZAÇÃO PARA COOPERAÇÃO E DESENVOLVIMENTO ECONÔMICO (OCDE). Modernising government: the way forward. Paris: OECD Publishing, 2005.

ORGANIZAÇÃO PARA COOPERAÇÃO E DESENVOLVIMENTO ECONÔMICO (OCDE). Relatórios Econômicos OCDE: Brasil. 2018

ORGANIZAÇÃO PARA COOPERAÇÃO E DESENVOLVIMENTO ECONÔMICO (OCDE). The OECD recommendation of the council on open government. 14 December 2017 - C (2017)140 C/M (2017)22.

PARCERIA PARA GOVERNO ABERTO (OGP). Guidance Note. Washington, DC: OGP, 2015. Disponível em https://www.opengovpartnership.org/documents logp-handbook-rules-and-guidance-forparticipants-2020/ Acesso em 15 set. 2020

PARCERIA PARA GOVERNO ABERTO (OGP) Participation \& Co-creation Standards. Washington, DC: OGP, 2017. Disponível em https://www.opengovpartnership.org/ogpparticipation-co-creationstandards/\#: :text=OGP\%20Participation $\% 20 \mathrm{an}$ $\mathrm{d} \%$ 20Co\%2DCreation \%20Toolkit\&text $=$ Put $\% 2$ 0simply\%2C\%20the\%20collaboration\%20of,im plementing\%20lasting\%20open\%20government \%20reforms. Acesso em: 15 set. 2020

PARCERIA PARA GOVERNO ABERTO (OGP). The Open Government Declaration. Disponível em http://www.opengovpartnership.org/about/opengovernment-declaration. Washington, DC: OGP, September 2011 Acesso em: 15 set. 2020

PARKS, Wallace. The open government principle: applying the right to know under the Constitution. The George Washington Law Review, v. 26, n. 1, p. 1-22, 1957.

Peters, B. Guy. Os dois futuros do ato de governar: processos de descentralização e recentralização no ato de governar. Revista do Serviço Público, Brasília, v. 59, n. 3, p. 289307, jul./set. 2008.

PIERRE, JON. Debating governance: authority, steering, and democracy. Oxford University Press, 2000.

POLLIT, Christopher. Managerialism and the public service. Oxford: Blackwell, 1990.

RosenaU, James N.; CZEMPIEL, Ernst-Otto. Governança sem governo: ordem e transformação na política mundial. Brasília: Ed Unb e São Paulo: Imprensa Oficial do Estado, 2000 .

SCHUMPETER, J. Theory of economic development. Cambridge: University Press, 1934.

SHKABATUR, Jennifer. Transparency with (out) accountability: open government in the United States. Yale L. \& Pol'y Rev., v. 31, p. 79, 2012. 
STEIBEL, F. Brazil Mid-Term Self-Assessment 2016-2018. 2017. s/l: Open Government Partnership. 2017 Disponível em: < https://www.opengovpartnership.org/wpcontent/uploads/2018/10/Brazil_MidTerm_Report_2016-2018_EN.pdf> Acesso em: 15 set. 2020

TRIBUNAL DE CONTAS DA UNIÃO (TCU). 10 passos para a boa governança. Brasília: TCU, 2014.

Tribunal de CONTAS DA UniÃo (TCU). Acórdão 1273/2015. Brasília: TCU, 2015.

TRIBUNAL DE CONTAS DA UNIÃO (TCU). Referencial Básico de Governança aplicável à órgãos e entidades da administração pública $e$ ações indutoras de melhoria. Brasília: TCU, 2013.

UNITED NATIONS. Unlocking the human potential for public sector performance. World Public Sector Report 2005. New York: Department of Economic and Social Affairs, 2005.

United Nations. World Public Sector Report on Responsive and Accountable 2015. New York: Department of Economic and Social Affairs, 2015

\section{Cristina Borges Mariani}

iD https://orcid.org/0000-0002-7894-1703

Mestre em Políticas Públicas e Desenvolvimento pelo Instituto de Pesquisa Econômica Aplicada (Ipea). Analista de Políticas Sociais (Ministério da Cidadania).

E-mail: cbmariani@gmail.com

\section{Antonio Lassance}

https://orcid.org/0000-0003-0647-4963

Pesquisador do Instituto de Pesquisa Econômica Aplicada (Ipea), Doutor em Ciência Política pelo Instituto de Ciência Política da Universidade de Brasília (UnB). Professor colaborador da Escola Nacional de Administração Pública (Enap).

E-mail: antonio.lassance@ipea.gov.br
UnITED STATES OF AMERICA (USA). President's memorandum on transparency and open government - interagency collaboration. USA, 2009.

WeISS, Carol. Evaluation: methods for studying programs and policies. 2. ed. Upper Saddle River: Prentice Hall, 1998.

WORLD BANK. Governance and Development. Washington: World Bank, april 1992.

WORLD BANK. Reforming public institutions and strengthening governance: a world bank strategy. Washington, DC: World Bank, 2000.

World BANK. Sustainable Development Goals and Open Data. 2015.

WORLD BANK. World Bank's report, SubSaharan Africa: from crisis to sustainable growth. 1989

WORLD BANK. World Development Report 2017: governance and the law. Washington: The World Bank, 2017.

YIN. R. K. Estudo de caso: planejamento e métodos. 3. ed. Porto Alegre: Bookman, 2005.

YU, H.; ROBRINSON, D. G. The new ambiguity of "Open Government". Rochester, NY: Social Science Research Network. 2012 